\title{
A Psicoterapia Socio-Histórica
}

The Socio-Historical Psychotherapy

La Psicoterapia Socio Histórica
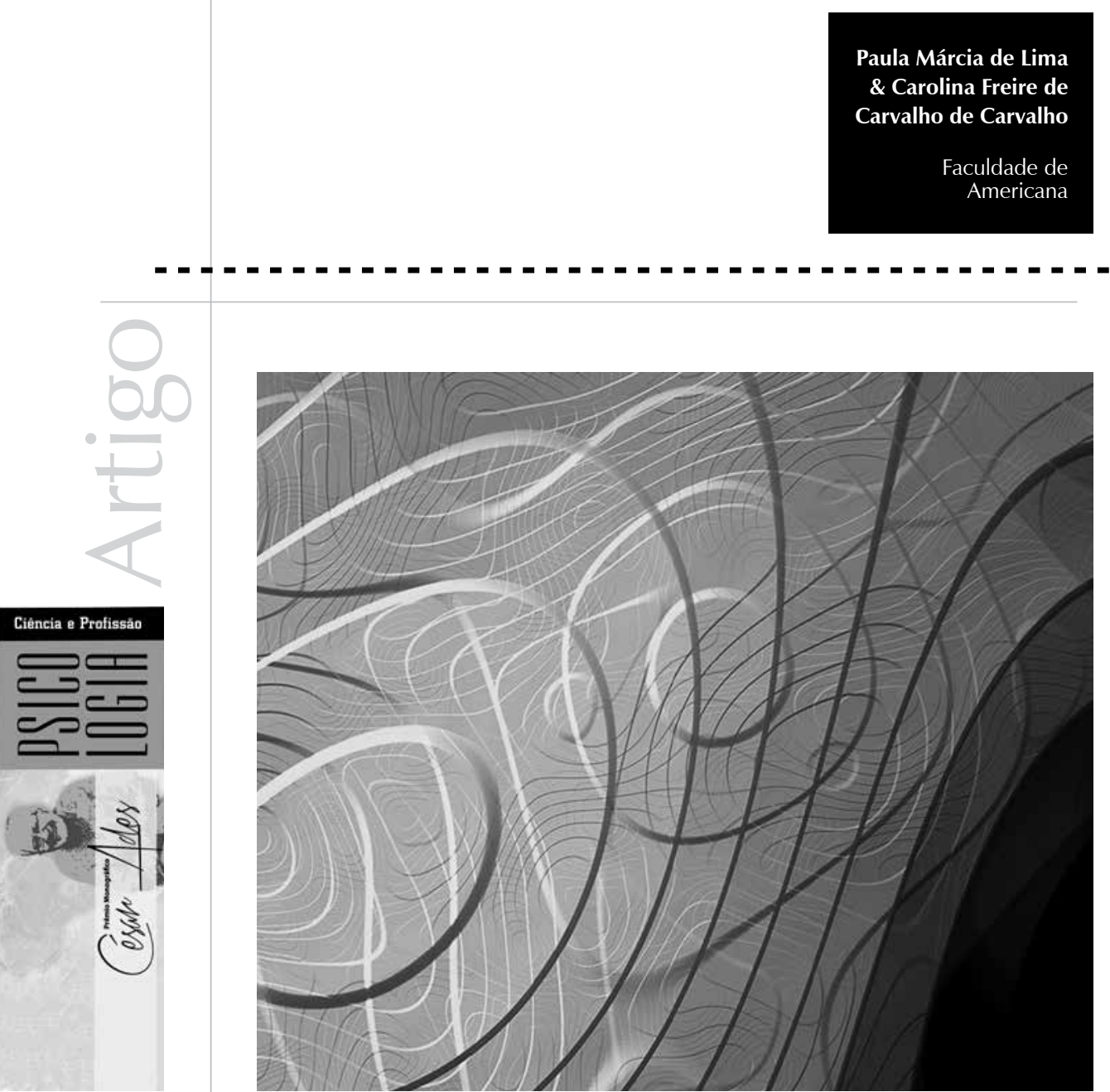
Resumo: Este trabalho teve como objetivo desvelar a possibilidade da aplicação da abordagem sociohistórica à psicoterapia, e foi realizado através de um ensaio teórico a partir de uma pesquisa bibliográfica e da análise de publicações de estudiosos da teoria socio-histórica, que compreende o homem a partir da teoria marxista de que o homem constrói e é construído nas relações sociais. A análise fenomenológica corroborou a dinâmica da internalização dos conceitos pela pesquisadora, possibilitando a expressão do que foi entendido ao longo de todo o trabalho através das diferentes categorias em diferentes momentos: imersão, que é o momento da leitura, discriminação e atribuição de sentidos, referente ao momento de organização do material de forma subjetiva e singular, e, finalmente, a síntese, que busca a compreensão geral obtida através das etapas anteriores. Assim, a possibilidade de uma psicoterapia socio-histórica foi identificada na literatura estudada e analisada pela pesquisadora.

Palavras-chave: Psicologia. Psicoterapia. Fenomenologia. Vygotsky, Lev Semenovich, 1896-1934.

Abstract: This article is the result of a psychology course paper that proposed to reveal the possibility of applying the socio-historical approach to psychotherapy, since we observed the lack of publications in sociohistorical psychotherapy, for most publications refer only to the educational applications of this theory. The socio-historical psychology understands man from the marxist dialectic, that assumes that man is constructed and constituted in social relations. Written as a theoretical essay, we used the method of bibliographical survey of books and journals produced in Brazil and the analysis of scholar publications on the subject. The chosen method of analysis was the phenomenological, allowed by the categories: immersion (for the time of reading), discrimination and assignment senses (regarding the subjective organization of the material) and synthesis (that seeks general understanding), internalizing the concepts read. This way, the possibility of a socio-historical approach in psychotherapy was identified and analyzed in the literature.

Keywords: Psychology. Psychotherapy. Phenomelogy. Vygotsky, Lev Semenovich, 1896-1934.

Resumen : Este trabajo tuvo como objetivo desvelar la posibilidad de la aplicación del abordaje socio histórico a la psicoterapia, y fue realizado a través de un ensayo teórico a partir una investigación bibliográfica y del análisis de publicaciones de estudiosos de la teoría socio histórica, que comprende el hombre a partir de la teoría marxista de que el hombre construye y es construido en las relaciones sociales. El análisis fenomenológico corroboró la dinámica de la internalización de los conceptos por la investigadora, posibilitando la expresión de lo que fue entendido a lo largo de todo el trabajo a través de las diferentes categorías en diferentes momentos: inmersión, que es el momento de la lectura, discriminación y atribución de sentidos, referente al momento de la organización del material de forma subjetiva y singular, $y$, finalmente, la síntesis, que busca la comprensión general obtenida a través de las etapas anteriores. Así, la posibilidad de una psicoterapia socio histórica fue identificada en la literatura estudiada y analizada por la investigadora.

Palabras clave: Psicología. Psicoterapia. Fenomelogía. Vygotsky, Lev Semenovich, 1896-1934

Este trabalho visa a estudar a aplicação da abordagem socio-histórica como psicoterapia bem como entender a abordagem criada por Vygotsky, uma vez que parte não só do materialismo histórico dialético de Marx e de conceitos como filogênese, sociogênese e ontogênese, mas apresenta-nos também os conceitos de processos psicológicos elementares para explicar que é deles que descendem os processos psicológicos superiores, e que estes só são possíveis no momento em que existem os instrumentos e, em consequência, os signos para que ao mesmo tempo produzam a mediação e, em seguida, a internalização.

Assim, o presente estudo busca, através de um ensaio teórico inserido em um trabalho de conclusão de curso (TCC), discutir a teoria socio-histórica, abordagem da Psicologia em que o homem é compreendido como um ser ativo no mundo, ou seja, o constitui e é constituído por ele, dentro de um campo pouco divulgado, ou que, pelo menos, possui pouco material científico publicado no que se refere ao trabalho clínico, ou psicoterapia.

A Psicologia socio-histórica foi criada em meio à Revolução Russa. Com base na teoria marxista, podemos entender isso quando Veer e Valsiner (2001) afirmam que, como aspecto fundamental, Vygotsky usa o pensamento marxista para dizer que os seres humanos diferem dos animais no momento em que têm uma história social e coletiva, não se adaptando passivamente à natureza, 
Os signos são como se fossem os instrumentos, mas usados no campo psicológico. Oliveira (2002) explica que 0 signo age como instrumento na atividade psicológica, da mesma forma que a ferramenta em um trabalho manual, por exemplo. pois fazem uso de instrumentos no processo de trabalho. Outra ideia, vinda da teoria de Marx, foi a experiência duplicada, que consiste na capacidade do homem de prever os resultados, ou seja, o homem é capaz de pensar nas consequências de seus atos, e com isso ponderar qual seria a melhor ação.

Vygotsky é tido também como um psicólogo interacionista por levar em consideração o plano filogenético, que é a história da espécie, para entender como se originam os processos que hoje são tipicamente humanos (Oliveira, s/d): o sociogenético, que é a história da cultura onde o sujeito está inserido (a autora acrescenta que esse plano não diz respeito somente a país, mas também a classe social, valores, família, tipos de pares ou até mesmo a convivência religiosa), e o plano ontogenético, que trata da história do desenvolvimento do indivíduo como Ser desde seu nascimento; a ontogênese atenta não para o que o sujeito aprendeu, mas para como ele aprendeu.

Com os estudos de Rego (1995), é possível entender que um dos conceitos mais abrangentes de Vygotskyé o de que os processos psicológicos superiores - que correspondem aos funcionamentos tipicamente humanos, tais como imaginação, planejamento, memória ativa, pensamento abstrato, atenção voluntária, ações conscientemente controladas, pensamento abstrato, raciocínio dedutivo e capacidade de planejamento têm sua origem no meio histórico e cultural (sociogênse e ontogênese), emergindo dos processos psicológicos elementares.

Vygotsky lança mão do materialismo histórico dialético não só para desenvolver seu conceito como também para explicá-lo, pois ele afirma que os processos psicológicos superiores têm sua origem nas relações sociais, assim, entende que o sujeito não é um mero receptáculo, mas é produtor e produzido pelo contexto em que vive.
É com os processos psicológicos superiores que Vygotsky apresenta um conceito relacionado a outro, pois não há internalização se não houver mediação, sendo que os dois estão intrinsecamente ligados aos processos psicológicos superiores. "Mediação, em termos genéricos, é o processo de intervenção de um elemento intermediário numa relação; a relação deixa, então, de ser direta e passa a ser mediada por esse elemento" (Oliveira, 2002, p. 26).

Vygotsky acreditava que a relação do homem com o mundo é uma relação fundamentalmente mediada, e destacou dois tipos de elementos mediadores, que são os instrumentos e os signos.

O instrumento é um elemento interposto entre o trabalhador e o objeto de seu trabalho, assim amplia a possibilidade de transformação do ambiente.

Os signos são como se fossem os instrumentos, mas usados no campo psicológico. Oliveira (2002) explica que o signo age como instrumento na atividade psicológica, da mesma forma que a ferramenta em um trabalho manual, por exemplo.

Nesse processo, há também a internalização, que é outro conceito básico da teoria de Vygotsky. O processo de internalização é alcançado por dois movimentos: o primeiro, com a utilização de marcas externas, transforma-se em processos internos de mediação, ou ainda, são desenvolvidos sistemas simbólicos, que organizam os signos em estruturas complexas e articuladas.

Goes (2000) afirma que, para Vygotsky, o sujeito constitui suas formas de ação e sua consciência nas relações sociais; dessa forma, a ação do sujeito é considerada a partir da ação entre sujeitos. O plano psicológico, portanto, só pode ser compreendido nas suas dimensões social, cultural e individual. 
Assim, o desenvolvimento é alicerçado no plano das interações, ou seja, é socialmente construído, e, nesse plano, é possível entender que os sistemas simbólicos, e principalmente a linguagem, exercem papel essencial na comunicação e na constituição de significados compartilhados que consentem interpretações de objetos, eventos e situações do mundo circundante.

A linguagem como um todo, ou seja, todas as suas formas ocupam lugar central na teoria de Vygotsky, uma vez que é um sistema simbólico básico de todos os grupos culturais. Outro fator que a torna importante para a teoria é o surgimento do pensamento verbal e da linguagem, porque é o momento em que o biológico se transforma em sociohistórico (Oliveira, 2002).

Vygotsky também introduziu dois níveis de desenvolvimento: nível de desenvolvimento real, "o nível de desenvolvimento das funções mentais da criança que se estabeleceram como resultado de certos ciclos de desenvolvimento já completados" (Vygotsky, 2007, pp. 95-96), ou seja, é o que o indivíduo consegue fazer de forma autônoma, independentemente do auxílio de qualquer outro sujeito, enquanto o nível de desenvolvimento potencial se refere à resolução de problemas sob a orientação de outro indivíduo mais capacitado ou com mais experiência naquela tarefa. O grande diferencial da teoria de Vygotsky é a zona de desenvolvimento proximal, que define as funções que ainda não amadureceram, mas que estão em processo de amadurecimento (Vygotsky, 2007).

Portanto, sendo a psicoterapia uma relação contínua de troca e de transformação, por que não encontramos tantos profissionais atuando a partir dessa abordagem na clínica, ou que não divulgam seu trabalho? A isso, Rey (2007, p. 198) atribui o fato de Vygotsky ter chegado à Psicologia ocidental através da sua significação do desenvolvimento da Psicologia social apoiada no marxismo; assim, questões da personalidade, do sujeito e da patologia, que são aspectos centrais para o desenvolvimento de uma posição na clínica, foram pouco trabalhados.

A partir disso, é importante ressaltar que Veer e Valsiner (2001) contribuem com informações a partir de pesquisa sobre vida e a obra de Vygotsky, afirmando que suas últimas pesquisas buscaram instruir-se mais sobre o comportamento desviante de adultos, tendo ele passado a estudar mais profundamente sobre psiquiatria, Psicologia clínica ${ }^{1}$. Para esses autores, fica claro que a teoria socio-histórica foi uma das muitas teorias que tentaram dar explicações a respeito da origem e do desenvolvimento dos processos mentais de adultos.

Dias afirma que "as práticas clínicas atuais apontam um maior interesse e preocupação com o contexto social" (2005, p.2), e acrescenta que esse novo olhar faz repensar a postura de profissionais diante do ato clínico, no sentido de que é a subjetividade de uma construção social e histórica. O autor assegura também que "a psicoterapia é uma forma recorrente de interação/relação social, e seu espaço de ocorrência são os espaços psicólogos, lugar da realidade de cada um" (2005, p.3).

Sendo assim, a psicoterapia é inerente à atividade do psicólogo clínico e de todos aqueles que, de alguma forma, trabalham em saúde, incluindo o âmbito da saúde pública. Trata-se de uma modalidade importante de intervenção em Psicologia diante do sofrimento humano (Quayle, 2007).

Mas, pensando no sentido da práxis, temos a Resolução no 10/00, de 20 de dezembro de 2000, do Conselho Federal de Psicologia (CFP), cujo artigo primeiro estabelece que a psicoterapia é prática do psicólogo, e constitui 


\section{De acordo com \\ Appolinário, \\ "a análise \\ fenomenológica individuais ou grupais. \\ Objetivo}

buscará uma

compreensão

das temáticas

que emergem

pelo contato da

consciência do

pesquisador com

o texto analisado"

(2006, p. 170);

dessa forma, a

pesquisadora

perpassou

o material

pesquisado,

proporcionado

pela construção da análise.

Este trabalho estudou a possibilidade de a psicoterapia socio-histórica ser utilizada na clínica. A partir de uma revisão bibliográfica, buscou-se uma possível resposta para a escassez de material literário nesse campo, já que literatura a respeito dessa abordagem no campo educacional e no campo social, separadamente, não são difíceis de encontrar no caso de realização de uma pesquisa.

\section{Justificativa}

um processo científico de compreensão, análise e intervenção que se realiza através de técnicas e de métodos psicológicos que promovem a saúde mental e que proporcionam condições de enfrentamento de conflitos ou de transtornos psíquicos

A escolha do tema foi feita a partir de dúvidas que foram surgindo em estudos paralelos à graduação a respeito da Psicologia sociohistórica, pois muito se encontrava sobre o desenvolvimento infantil, o campo social e o trabalho feito no campo da educação, mas, sobre a psicoterapia a partir dessa abordagem, é possível encontrar somente um trabalho escasso, até o momento de uma busca mais refinada. Nesse trajeto, a pesquisadora se deparou com a seguinte pergunta: é possível a psicoterapia sociohistórica?

Pensando ainda na importância do tema, fez uma avaliação crítica sobre toda a sua graduação, e chegou à conclusão que esse trabalho se torna importante no momento em que vemos um novo método, pois é importante o conhecimento a respeito de outras abordagens para o psicólogo que não aquelas já arraigadas, que não permitem novas possibilidades de lidar com o sofrimento humano.

\section{Metodologia}

\section{Sujeito}

Os sujeitos deste trabalho foram todas as literaturas já estudadas e pesquisadas durante a graduação em Psicologia referentes à Psicologia socio-histórica, como, por exemplo, artigos, livros e sites.

\section{Método de coleta}

Foi feito um levantamento bibliográfico de artigos em bases de dados científicas, como, por exemplo, Scielo, livros e sites de Psicologia, o que tornou este trabalho um ensaio teórico, ou uma pesquisa documental (Appolinário, 2006).

\section{Método de análise}

A análise partiu de livros e artigos publicados por Gonzáles-Rey $(2007,2001)$ e por Rego (1995), entre outros autores que publicaram em torno do tema psicoterapia sociohistórica.

A partir disso, foi utilizado um dos modelos de análise fenomenológica. De acordo com Appolinário, "a análise fenomenológica buscará uma compreensão das temáticas que emergem pelo contato da consciência do pesquisador com o texto analisado" (2006, p. 170); dessa forma, a pesquisadora perpassou o material pesquisado, proporcionado pela construção da análise.

O primeiro momento é chamado por Appolinário (2006, p.171) de imersão, referente ao momento da leitura do material, quantas vezes a pesquisadora julgar necessário para familiarizar-se com a linguagem. Em seguida, será o momento de discriminação e atribuição de sentido, para se organizar o material de acordo com o significado encontrado por ele mesmo, bem como para proceder a uma interpretação dessas unidades 
de significados a partir de suas concepções teóricas e subjetivas; por último, o momento de síntese, que consiste no mapeamento das unidades de sentido obtidas, objetivando alcançar a compreensão geral do fenômeno pesquisado, que parte da própria consciência da pesquisadora.

\section{Análise e discussão}

A partir da análise fenomenológica, foi possível atribuir sentido aos seguintes conceitos: de acordo com Rego (1995), o intuito de Vygotsky não era apenas desenvolver uma teoria sobre o desenvolvimento infantil, mas sobre o desenvolvimento humano, por isso recorre à infância, e justifica sua posição dizendo que o estudo da criança reside no fato de ela estar no centro da pré-história do desenvolvimento, principalmente pelo surgimento de instrumentos e da fala.

Sendo assim, Marangoni (2006) afirma que a psicoterapia socio-histórica atua a partir da compreensão do contexto social dos sujeitos, da interação de acontecimentos sociais, econômicos e políticos bem como constitutivos, e, de modo dialético, também constituintes dos sujeitos; assim, retira do sujeito o prognóstico de que suas dificuldades são causas intrínsecas e isoladas em si mesmas.

Nesse sentido, a psicoterapia socio-histórica é também interação social. GonzálesRey (2001) acrescenta a isso pontos que influenciam a prática nessa perspectiva, como a subjetividade construída historicamente, a ênfase no caráter singular, a consideração da subjetivação bem como dos sentidos e dos significados gerados nas relações, o reconhecimento do caráter constitutivo das patologias, a dúvida que o psicoterapeuta detém o poder supremo, isso porque a psicoterapia é um processo dialógico para que surjam mudanças produzidas a partir de uma relação dialógica (por isso a qualidade do diálogo é tão importante; por ser único em cada relação, o terapêutica é quem determina os processos de sentido e de significado para a produção de novos sentidos de subjetivação), e o objetivo de descobrir as configurações do sujeito, seguindo hipóteses que só terão sentido através da abertura de zonas de diálogo, que vão além de histórias narradas pelo sujeito.

Bock (2007) afirma que os psicólogos que atuam nessa vertente trabalham para romper os processos de fragilização no sujeito, já que a saúde psicológica do sujeito está na possibilidade de enfrentar cotidianamente seu contexto, interferindo nele, construindo soluções para os conflitos que se apresentam. O psicólogo, por exemplo, intervém na busca da construção de sentidos, isto é, nos registros que o sujeito faz do seu contexto, registros esses que podem ser as fontes de sua fragilidade.

Gonzáles-Rey (2007) acrescenta que o psicoterapeuta deve ser um facilitador de novas produções subjetivas alternativas que permitam novos processos de subjetivação. Essa subjetivação deve transformar-se em ações pelas quais o sujeito se torne responsável, produzindo ele mesmo novos espaços de sentido subjetivo.

Para tanto, é preciso levar em consideração o estilo de vida dos sujeitos da psicoterapia, entendendo seu estilo de vida como um "sistema de atividades que configuram a organização da vida cotidiana, o que constitui uma fonte relevante na configuração dos sentidos subjetivos das pessoas e dos espaços de relação" (Gonzáles-Rey, 2007, p.172).

Dias e Gonzáles-Rey concordam quando dizem que o psicólogo faz o papel de mediador, dando sentido ao problema do paciente, nomeando sentimentos, auxiliando na identificação de sentidos subjetivados e trabalhando junto na construção de novos 
1“Um dos três modelos de conduta do Dasein: Eigenwelt.

É o mundo-do-

si-mesmo. $\mathrm{O}$ autoconhecimento é uma qualidade exclusiva dos seres humanos, e conduz ao sentimento de autoidentificação. Este muda constantemente, mas forma uma série habitual de modelos de respostas autoidentificadoras e autovalorativas que podemos chamar de ser-em-si-mesmo.

$\mathrm{O}$ Eigenwelt, ou mundo-do-si-mesmo, tem também duas formas possíveis: (a) a forma singular, e (b) a forma anônima" (cf. Sá,2008). sentidos, logo a importância da função educativa e da interativa em contexto de práticas sociais diversas. Como exemplo dessas funções, associar a psicoterapia a espaços subjetivos de ação social: sala de aula, hospitais, tribunais, instituições de trabalho (pública ou privada), comunidades e grupos de diferentes formações. Afirma Gonzáles-Rey que "está claro que a psicoterapia pode ser realizada no consultório, o que não é certo é que não seja feita fora dele..." (2007, p.164).

\section{Técnica de psicoterapia socio- histórica}

Quintino-Aires (2006) acredita que o psicoterapeuta deva criar um conjunto de técnicas de intervenção adequadas para si próprio, já que também reconhece a construção mútua do desenvolvimento da psicoterapia. Mas o autor aborda também a importância dos conceitos de Vygotsky, como, por exemplo, a internalização, ou seja, através da mediação do psicoterapeuta, significados antes interpsicológicos passam a ser intrapsicológicos.

Com isso, seguem algumas técnicas usadas na psicoterapia socio-histórica: França $(\mathrm{s} / \mathrm{d})$ também considera importante observar a realidade do sujeito e a forma como ele percebe suas experiências, para que, a cada sessão terapêutica, possa desenvolver com os sujeitos, por exemplo, a zona de desenvolvimento proximal, a heterocronia, que se refere ao tempo que cada sujeito tem para a internalização de novos conceitos, a instigação, referente à estimulação de potencialidades, a contextualização, que coloca em contexto os mitos adquiridos pelo sujeito ao longo de sua vida, e a despotencialização, relativa à diminuição da potência de comportamentos ideais e fossilizados.
A zona de desenvolvimento proximal, já explicada antes neste trabalho, tornouse uma das mais utilizadas técnicas entre psicoterapeutas socio-históricos. Dias atribui esse fato ao valor que as capacidades emergentes têm para a abordagem. Assim, essas funções emergentes, ao longo da psicoterapia realizada a partir da mediação do psicoterapeuta, se tornam funções consolidadas, entrando para seu nível de desenvolvimento real.

Quintino-Aires (2011) e Marangoni (2012) também nomeiam algumas técnicas, com uma breve explicação ao que referem, como, por exemplo: intercurso mutuamente contingente, que é um padrão de interação relacional, estudado por Rita Leal (1975), compreensão empática, que consiste em assumir a Eigenwelt ${ }^{1}$ do paciente, reconhecendo e assumindo a subjetividade da sua representação de $\mathrm{Si}$ e do mundo, nomeação, que consiste em descrever e nomear o acontecer referido, repetição, que tem o objetivo de produzir maior verbalização, ou mesmo para o sujeito perceber sua fala através do outro, marcação, que tem o intuito de não deixar no vazio a palavra do outro, ou seja, apoia o diálogo, mas sem interromper o fala do sujeito, generalização, que procura reduzir a ansiedade, demonstrando semelhança de determinada ação em outros humanos, eco-emocional, que auxilia o sujeito a dar nomes a emoções e a sentimentos quando este demonstrar dificuldade em fazêlo, re-expressão, que descreve eventos apresentados pelo sujeito, mas de uma forma racional e objetiva, e pôr-verbo, quando se descreve um comportamento quando não houve linguagem verbal (mais usado com crianças).

Dias contribui com o modelo relacional dialógico, que trata do privilégio do acesso à pessoa total em um sentido psicosocio-emocional, e ainda integrando o 
desenvolvimento psicomotor, cognitivo e social. A mesma autora acrescenta que esse modelo tem como base a compreensão dos processos psicológicos e sua rede de significados, dialeticamente estabelecida pela significação das informações proveniente do meio externo e interno.

Outra técnica é a complementação de frases, usada por Rey como instrumento na ação terapêutica e na construção de hipóteses. Essa técnica age na identificação das configurações subjetivas envolvidas com os conflitos do sujeito, porque facilita ao sujeito falar sobre as questões que o afetam, bem como se torna uma interessante operação terapêutica no momento em que é associado à conversação.

Assim, Rego afirma que Vygotsky dedica especial atenção à linguagem, que é um sistema simbólico fundamental em todos os grupos humanos, que organiza os signos em estruturas complexas, desempenhando papel indispensável para a formação de características exclusivamente humanas.

Desse modo, a linguagem funciona como elemento mediador, permitindoa comunicação entre indivíduos e estabelecendo, assim, significados compartilhados por determinados grupos culturais, percepção e interpretação de objetos, eventos e situações do contexto, reafirmando que o processo de funcionamento mental humano é fornecido pela cultura, utilizando a mediação simbólica.

Para Vygotsky (2008), o desenvolvimento do pensamento é determinado pela linguagem, ou seja, pelos instrumentos linguísticos do pensamento, e pela experiência socio-cultural do sujeito durante sua infância. Assim, o desenvolvimento intelectual do sujeito (desde sua infância) depende de seu domínio dos meios sociais do pensamento, ou seja, da linguagem.
Na mesma obra, o autor destaca a compreensão da palavra, trabalho considerado muito delicado por psicoterapeutas socio-históricos, explicando que o pensamento e a linguagem são as chaves para a compreensão da natureza da consciência humana, porque as palavras desempenham papel central na evolução histórica da consciência como um todo.

França (s/d) e Dias (2005) esclarecem que, para se ter êxito na clínica, é preciso ter a linguagem como instrumento de mediação, isso porque a comunicação do sujeito é produto de sua consciência e de sua experiência. Essa consciência pode visualizar imagens, obter sensações e fantasias, mas, se o sujeito não externalizar essas emoções e afetos através da palavra, a psicoterapia não terá sentido, e o psicoterapeuta não fará seu papel fundamental de mediador.

Vygotsky acrescenta que um conceito expresso por uma palavra pode representar um ato de generalização, mas os significados, ao contrário, diferenciam-se para cada sujeito.

Rey acrescenta que, por trás das narrativas, estão os sujeitos, que são sujeitos pensantes e atuantes em seu contexto, portanto, históricos também; assim, cada uma de suas afirmações contém significado cultural e sentidos construídos ao longo de suas histórias.

O autor comenta ainda sobre um momento essencial na psicoterapia, quando se assume uma definição ontológica da subjetividade, porque o conflito está além da organização da fala, existindo, assim, sentidos subjetivos que muitas vezes não são representados de forma consciente pelo sujeito. Não será produzida mudança terapêutica se não houver novas cadeias de desdobramentos simbólicoemocionais que organizem novos sentidos subjetivos (Gonzáles-Rey, 2007).

Dessa maneira, a psicoterapia deve ter o objetivo de colocar o sujeito subordinado à 
sua experiência, para que tenha, assim, a capacidade de produzir sentidos subjetivos alternativos àqueles relacionados ao seu sofrimento.

Ratner (1995) concorda com GonzálesRey acrescentando que a Psicologia sociohistórica é capaz de explicar a loucura ou psique geradora de danos bem como os outros fenômenos psicológicos, pois entende-se que o funcionamento gerador de danos segue os mesmos princípios sociohistóricos do funcionamento saudável.

Gonzáles-Rey (2011) acrescenta que o transtorno mental não é uma doença de fato, no sentido biológico, mas é, na verdade, uma configuração subjetiva em processos da vida atual do sujeito, e que vão sendo acrescidos sentidos subjetivos a esses processos. Assim, nessa perspectiva, toma-se o cuidado de ir além das classificações centradas apenas nas patologias, dando ênfase ao trabalho psicoterapêutico, isso porque se reconhece que as atividades e as relações do sujeito sempre encontrarão formas de subjetivação, ou de capacidade geradora. De acordo com Gonzáles-Rey, "a capacidade geradora do sujeito é inseparável da produção de novos sentidos subjetivos de novas práticas. Esse processo é essencial na definição da psicoterapia e geral a todos os campos de práticas humanas" (2007, p.199).

\section{Considerações finais}

Ao longo do trabalho, fomos apresentados à teoria desenvolvida por Vygotsky, que, como alguns autores disseram, dentre eles Veer e Valsiner e Rego, estudou muito mais o desenvolvimento humano do que outros aspectos bem difundidos por outras teorias. O estudo voltado para a clínica tornou-se prioridade em sua vida próximo de sua morte. Assim, o que temos sobre psicoterapia socio-histórica é produção de seus seguidores, psicólogos vygotskyanos, que usam os conceitos criados por Vygotsky e aplicam-nos em seu trabalho clínico. Temos, portanto, a resposta para nossa pergunta inicial: Sim, é possível a psicoterapia sociohistórica, porque, na literatura pesquisada, encontramos psicólogos que trabalham com essa temática, apresentando os procedimentos e embasando-se teoricamente na abordagem socio-histórica.

Mas também foi encontrada uma escassez de material sobre o tema separadamente, ou seja, encontra-se o tema em meio a outros conceitos de Vygotsky, explicando seu trabalho da forma como é utilizado na Psicologia social ou na Psicologia educacional, o que nos remete a outra questão deste trabalho: talvez alguns profissionais que trabalhem com essa abordagem não divulgam seus métodos ou não produzem artigos científicos. 


\section{Paula Márcia de Lima}

Graduada em Psicologia pela Faculdade de Amaricana, Americana - SP - Brasil.

E-mail: psicopl@yahoo.com.br

\section{Carolina Freire de Carvalho de Carvalho}

Mestre em Psicologia Escolar pela Pontifícia Universidade Católica de Campinas e docente da Faculdade de Americana, Americana - SP - Brasil.

E-mail: carolfcc@gmail.com

\section{Endereço para envio de correspondência:}

Rua Seringueira, 366, Jardim Alvorada. CEP: 13460-000. Nova Odessa, SP.

Appolinário, F. (2006). Metodologia da ciência: filosofia e prática da pesquisa. São Paulo: Thomson.

Bock, A. M. B. (2007). A prática profissional em psicologia sócio-histórica. In A. M. B. Bock, M. G. M. Gonçalves, \& O. Furtado (Orgs.), Psicologia sócio-histórica: uma perspectiva crítica em Psicologia (pp. 15-35). São Paulo: Cortez

Conselho Federal de Psicologia. (2000). Resolução no 010, de 20 de dezembro de 2000. Especifica e qualifica a psicoterapia como prática do psicólogo. Brasília, DF: Autor.

Dias, M. H. S. S. M. (2005). A psicologia sócio-histórica na clinica: uma concepção atual em psicoterapia, Recuperado em 26 set., 2011 de http://www.ipaf.com.br/arquivos/artigos/ artigo_m_helena.pdf

França, A. (2011). Ensaio sobre a clínica sócio-histórica em Vygotsky. Recuperado em 26 set. 2001 de HTTP:// naborfranca.sites.uol.com.br/psicologia-clinica.

Goes, M. C. R. de. (2000). A natureza social do desenvolvimento psicológico. In E. Zamboni. Pensamento e linguagem. Estudos na perspectiva da psicologia soviética (3a ed., pp. 21-29). Campinas, SP: Cedes.

González-Rey, F. L. (2001). O enfoque histórico-cultural e seu sentido para a psicologia clínica: uma reflexão. In A. M. B. Bock, M. G. M. Gonçalves, \& O. Furtado (Orgs.), Psicologia sócio-histórica: uma perspectiva crítica em Psicologia (pp. 193-214). São Paulo: Cortez.

González-Rey, F. L. (2007). Psicoterapia, subjetividade e pósmodernidade: uma aproximação histórico-cultural. São Paulo: Thomson Learning.

González-Rey, F. L. (2011). Subjetividade e saúde: superando a clínica da patologia. São Paulo: Cortez.

Marangoni, S. \& Aires, J. M. Q. (2006). A psicologia sóciohistórica na formação de psicoterapeutas. Psicologia para América Latina, 6. Recuperado em 24 fevereiro, 2012 de http://psicolatina.org/Seis/sociohist.htm
Marangoni, S. (2012). Ludoterapia como um vygotskyano faz. Recuperado em 08 de agosto, 2012 de http://www.ipaf. com.br

Oliveira, M. K. de. (2002). Vygotsky: aprendizado e desenvolvimento: um processo sócio-histórico (4a ed.). São Paulo: Scipione.

Oliveira, M. K. de. (s.d.). Vygotsky, vida e obra. Recuperado em 26 setembro, 2011 de http://www.chasqueweb.ufrgs.br/ slomp/ vygotsky/colegio--vigotsky.htm

Quayle, J. (2007). A formação do psicólogo em psicoterapia: desafios. Recuperado em 19 abril, 2012 de http://www. abrap.org/site/ideias.html .

Quintino-Aires, J. M. (2006, fev.). A abordagem sócio-histórica na psicoterapia com adultos. Psicol. Am. Latina., 5. Recuperado em 17 de novembro de 2011 de http://www.psicolatina.org/ Cinco/adultos.html

Quintino-Aires, J. M. (2011). Psicoterapia vygotskyana. Recuperado em 26 setembro, 2011 de http://www.ipaf. com.br/.

Ratner, C. (1995). Loucura. In C. Ratner. A psicologia sóciohistórica de Vygotsky. Aplicações contemporâneas (pp. 206262). Porto Alegre: Artes Médias.

Rego, T. C. (1995). Vygotsky: uma perspectiva histórico-cultural da educação (17a ed.). Petrópolis, RJ: Vozes.

Veer, R. Van Der, \& Valsiner, J. (2001). Vygotsky: uma síntese (4a ed., C. Camargo Bartalotti, trad.). São Paulo: Edições Loyo

Vygotsky, L. S. (2007) A formação Social da mente.( 7a ed.) São Paulo: Martins Fontes. 